\title{
Irinotecan/Bevacizumab Regimen
}

National Cancer Institute

\section{Source}

National Cancer Institute. Irinotecan/Bevacizumab Regimen. NCI Thesaurus. Code C136258.

A chemoimmunotherapy regimen consisting of irinotecan and bevacizumab that is used for the treatment of colon cancer. 